\title{
Cognitive Behavioral Therapy as the Basis for Preventive Intervention in a Sleep Health Program: A Quasi-Experimental Study of E-Mail Newsletters to College Students
}

\author{
Kenichi Asano1*, Ikuo Ishimura², Hironori Abe2, Michiko Nakazato1, Akiko Nakagawa1, \\ Eiji Shimizu1 \\ ${ }^{1}$ Research Center for Child Mental Development, Graduate School of Medicine, Chiba University, Chiba, Japan \\ ${ }^{2}$ Department of Clinical Psychology, Tokyo Seitoku University, Chiba, Japan \\ Email: "kenichi.asano1225@gmail.com
}

Received 5 January 2015; accepted 26 January 2015; published 29 January 2015

Copyright (C) 2015 by authors and Scientific Research Publishing Inc.

This work is licensed under the Creative Commons Attribution International License (CC BY).

http://creativecommons.org/licenses/by/4.0/

(c) (i) Open Access

\section{Abstract}

Several reports suggest that college students often have atypical sleep patterns and experience poor sleep quality. We examined the effect of a cognitive behavioral therapy (CBT) based intervention program to improve sleep quality and overall mental health among college students. The intervention was delivered in the form of e-mail newsletters. Fifty-three students participated in the intervention group, and another 50 students participated in the control group. The intervention group received a lecture on sleep hygiene; once-weekly e-mail newsletters on sleep health topics (sleep hygiene, stimulus control, sleep restriction, sleep titration, and relapse prevention) and were asked to maintain a four-week sleep diary. The Pittsburgh Sleep Quality Index (PSQI), a measure of sleep quality, and the Kessler 6, a measure of psychological distress, were administered before the lecture (as the baseline measurement) and again 16 weeks later (follow-up measurement). PSQI and K6 scores were reduced in the intervention group compared with the control group. A CBT-based sleep health program utilizing e-mail newsletters may work to improve sleep quality and mental health. This program may represent a cost effective way for Japanese students to receive treatment for poor sleep and may also serve to prevent psychiatric problems.

\section{Keywords}

Sleep, College Students, Insomnia, Mental Health, Cognitive Behavioral Therapy

\footnotetext{
*Corresponding author.

How to cite this paper: Asano, K., et al. (2015) Cognitive Behavioral Therapy as the Basis for Preventive Intervention in a Sleep Health Program: A Quasi-Experimental Study of E-Mail Newsletters to College Students. Open Journal of Medical Psychology, 4, 9-16. http://dx.doi.org/10.4236/ojmp.2015.41002
} 


\section{Introduction}

Several studies suggest that college students often suffer from chronic poor sleep quality and daytime sleepiness [1]. Previous study of medical students, $17.3 \%$ of the sample reported abnormal levels of daytime sleepiness, with another 13.3\% experiencing borderline impairment in this area [2]. In Canada, 75.6\% of university students reported inadequate sleep [3]. The development of the Internet seems to have made an already common problem worse. High use of e-mail or online chatting can disturb sleep, leading to worse mental health [4]. Further technological developments may only compound the problem.

\subsection{Sleep Problems Induce Undesirable Effects on Academic Performance and Mental Health}

Sleep problems have direct detrimental effects. In addition, they can also adversary affect both academic performance and mental health. For example, poor sleep can impair learning performance [1]. Daytime sleepiness is associated with poor academic performance in college students [5]. Over $60 \%$ of students in one study were categorized as poor-quality sleepers, with these individuals reporting more problems with physical and psychological health [6]. A report using DSM-5 criteria showed that 9.5\% of college students suffer from chronic insomnia. They also reported worse sleep, fatigue, depression, anxiety, stress and reduced quality of life, as well as greater hypnotic and stimulant use for sleep problems [7]. Poor sleep can lead to depression and is a significant risk factor for this condition [8]. College students with depressive symptoms and sleep disturbance also frequently experience anxiety symptoms and hyper-arousal, with corresponding impairments in functioning [9]. It seems clear that sleep problems are a significant risk factor for the development of mental health problems in college students, particularly depression and anxiety.

\subsection{Intervention for Sleep Problems}

Cognitive behavioral therapy for insomnia (CBTI) is a popular treatment for sleep disturbance [10]. CBTI and similar interventions produce reliable changes in several sleep parameters of individuals with either primary insomnia or insomnia associated with medical and psychiatric disorders [11]. For older adults, CBTI can provide greater and more prolonged beneficial effects than sleep medications [12]. It was found that a form of short-term CBTI dubbed brief behavioral therapy was effective for the treatment of sleep disturbance and mood symptoms in cases of residual depression [13]. Despite its demonstrated effectiveness, CBTI is significantly underutilized, likely due to a limited number of trained providers and experts [14].

\subsection{Improvement of Accessibility for CBTI}

Internet-based treatment options and stepped-care models might be feasible treatment options, largely due to cost effectiveness and increased accessibility [15]. A randomized controlled trial of a 5-week online CBTI intervention revealed significant improvement on measures such as total sleep time, time awake in the middle of the night and sleep efficiency, although an individual CBTI group also showed improvement, with effect sizes similar across the groups [16]. It was shown improvements in self-reported sleep quality after internet-delivered CBTI, with gains maintained at 6-month follow-up [17]. These results show the use of internet CBTI with automated support and a community forum is effective in improving the sleep and associated daytime functioning of adults with insomnia disorder [18]. Thus, unsupported self-help CBTI could be an effective first option offered in a stepped care approach when treating insomnia [19].

\subsection{Accessible Sleep Treatment for College Students}

For college students, it is important not only to treat existing insomnia, but also to prevent sleep problems, depression and related psychiatric disorders. Knowledge of sleep hygiene is related to sleep practices, which also contributes to the quality of sleep [20], and in one study, psychological education about sleep improved sleep quality and sleep hygiene behaviors at 6 weeks post treatment [21]. Intervention offered in introductory college psychology courses accompanied by supplemental online instruction can improve knowledge concerning sleep and sleep health, and increase the likelihood that students improve their personal sleep habits [22]. A previous study showed that eight weeks of e-mail delivered cognitive behavioral therapy (CBT) targeting sleep health 
improved sleep quality and reduced depressive symptoms in students with poor sleep, but potential preventative benefits were not assessed here because no healthy participant sample was included [23].

The purpose of the present study was to develop and validate a CBTI-based program that can be used both to treat students already experiencing poor sleep and prevent students with good sleep from subsequently developing sleep or sleep-associated psychiatric problems such as depression. We developed a relatively short fourweek intervention based on brief behavioral therapy [13], shown to produce robust effects in four weeks and likely to be more suitable for college students with good sleep, a population who may not demonstrate high levels of interest and motivation to engage in psychological treatment. We expected to observe prophylactic effects on both sleep problems and depression, given that brief behavioral therapy is efficacious in both cases. The brief behavioral therapy program was modified to make it suitable for use as an e-mail delivered program.

\section{Method}

We conducted a quasi-experimental study. The study was approved by the ethics committee of Tokyo Seitoku University (No. 13-5) and conforms to the Declaration of Helsinki. Informed consent was obtained. Data were collected and analyzed pseudonymously. This study was registered in the national UMIN Clinical Trials Registry (ID: UMIN000012471).

\subsection{Participants}

All participants were recruited from two introductory psychology classes in the same college. In one class, students were asked to complete the baseline questionnaire assessment and then received a sleep hygiene lecture as a part of the course. Students in this class were then invited to take part in an additional e-mail based program. Sixty-six students of the 87 attendees agreed to complete the baseline assessment and participate in the e-mail program. Students in the second class underwent a similar recruitment procedure, except that they did not receive the sleep hygiene lecture. Fifty-seven of 83 attendees agreed to participate. In total, 66 students participated in sleep hygiene and e-mail group (intervention group) and 57 participated in the control group at baseline. The intervention group included 49 females (72\%) and the control group included 27 females (46\%).

The sample size was based on a power analysis conducted for PSQI scores. The effect size was estimated from previous studies on sleep hygiene and preventive interventions.

In the previous study, a self-help book treatment for insomnia yielded a Cohen's $d$ of 0.61 at 3 months followup [24]. We expected a comparable effect size $(d=0.6)$. Power calculations were performed using $G *$ Power software version 3.0.3 [25]. In order to detect an effect size of 0.60 or greater at an alpha error rate of 0.05 and a beta error rate of 0.20 , the estimated sample size was 45 participants per arm. Based on previous studies showing dropout rates of around 30\%, we derived a necessary sample size of 65 participants per arm [21].

\subsection{Materials}

The baseline survey included a demographic information questionnaire, the Japanese version of the Pittsburgh Sleep Quality index (PSQI-J), and the Japanese version of the Kessler 6 (K6).

The Pittsburgh Sleep Quality Index (PSQI) is one of the most widely used standardized questionnaires to assess subjective sleep quality [26]. The PSQI-J is a validated self-report questionnaire that assesses sleep quality and disturbances over a one-month time interval. The 19 items in the index comprise seven component scores that reflect subjective sleep quality and disturbances. The sum of the scores for these seven components yields a global sleep quality score with a range of 0 - 21 points. Using a cut-off point of 5.5 for PSQI-J global scores, one investigation found sensitivity and specificity values of $85.7 \%$ and $86.6 \%$ of primary insomnia, and $80.0 \%$ and 86.6\% for major depression [27].

The K6 is a self-report questionnaire used to screen for common mental disorders and based on modern item response theory methods. This measure consists of questions that are maximally discriminative of respondents in the 90th - 99th percentile range of the general population distribution, because it is known that between $5 \%$ $10 \%$ of the population suffer from mental disorders at any point in time [28]. The Japanese version of the K6 is valid for the assessment of psychological distress over a 30-day interval. The sum of scores for 6 items, each rated on a 5-point Likert scale, yields a psychological distress score that ranges from 0 - 30 points. The K6 has been found to work as well as or better than some other widely used screening questionnaires [29]. 


\subsection{Procedure}

The present set of interventions included sleep hygiene education provided via in-class lecture (Table 1) and additional e-mail intervention (encompassing stimulus control, sleep restriction, sleep titration and relapse prevention). Participants in the intervention group were also asked to keep a sleep diary. E-mails were delivered once-weekly for 4 weeks (Table 2).

\subsection{Data Analysis}

Descriptive statistics and bivariate correlations were calculated for all study variables. Paired $t$-tests and effect sizes (Cohen's $d$ for paired values) were used to compare values before and after the intervention within each condition. ANCOVA was then conducted to examine the effects of intervention on PSQI and K6 scores, with baseline assessment results as covariate. Effect sizes and 95\% confidence intervals were calculated using Cohen's $d$, calculated by dividing the difference between intervention and control group means at follow-up assessment by the pooled SD.

All statistical analyses (excluding power analysis) were performed using EZR (Saitama Medical Center, Jichi Medical University, Saitama, Japan), which is a graphical user interface for R (The R Foundation for Statistical Computing, Vienna, Austria) [30].

\section{Results}

Figure 1 shows a recruitment flow chart for this study. Dropout rates were $20 \%$ in the intervention group and

\section{Table 1. Sleep hygiene education contents.}

\begin{tabular}{cc}
\hline Number & 10 contents of sleep hygiene education \\
\hline 1. & Do not worry about sleep time. Amount of sleep needed is different from person to person. \\
2. & Pursue regular physical activity or exercise. \\
3. & Sleep in a room without lights or sounds. \\
4. & Avoid the use of caffeinated products after 3 p.m. \\
5. & Avoid the use of alcohol within 2 hours before going to sleep. \\
7. & Avoid smoking within 2 hours before going to sleep. \\
8. & Do not bring worries to bed. \\
9. & Do not actively pursue falling asleep and looking at the clock. \\
10. &
\end{tabular}

Table 2. E-mail contents.

\begin{tabular}{|c|c|c|}
\hline Week & Contents & Description \\
\hline 1 & Sleep hygiene & Do not worry about sleep time. Amount of sleep needed is different from person to person. \\
\hline 2 & $\begin{array}{l}\text { Sleep restriction } \\
\text { Stimulus control }\end{array}$ & 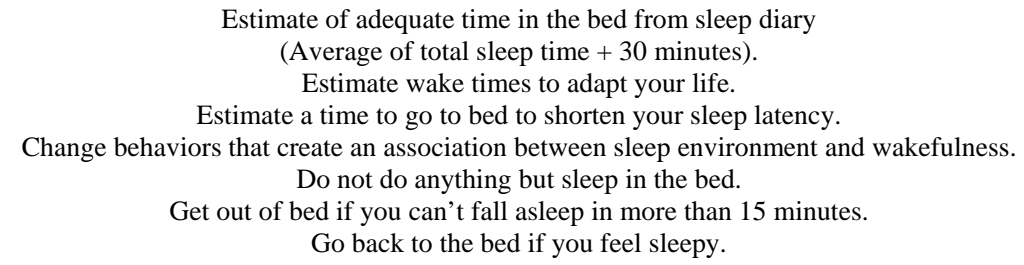 \\
\hline 3 & Sleep titration & Check your treatment gains and compliance and modify your sleep schedules or goals. \\
\hline 4 & Relapse prevention & Review own efforts and plan to maintain healthy sleep habits. \\
\hline
\end{tabular}


$13 \%$ in the control group, from baseline assessment to follow-up assessment.

Table 3 gives sex, age and clinical variables for the participants. $\chi^{2}$-tests with residual analysis for sex revealed differences between groups, $\chi^{2(1)}=6.15 ; p=0.01$. Participants in each group were compared using $t$-tests for age and other continuous measures. No differences were found between the groups for sleep quality/disturbances and mental health status.

ANCOVA revealed a significant main effect of group (intervention group vs control group) on both PSQI ( $F$ $(1,98)=10.75, p<0.01)$ and $\mathrm{K} 6(F(1,98)=8.85, p<0.01)$ scores.

Table 4 presents changes on the score of PSQI and K6 from baseline assessment for follow-up assessment. On PSQI the analysis of data found significantly greater efficacy for intervention group over control group ( $p=$ 0.00 ), with an effect size $(d)$ for intervention against control of 0.59 (95\% $C I=0.19$ to 0.99$)$. On K6 the analysis of data found significantly greater efficacy for intervention group over control group $(p=0.00)$, with an effect size $(d)$ for intervention against control of 0.61 ( $95 \% C I=0.21$ to 1.01 ).

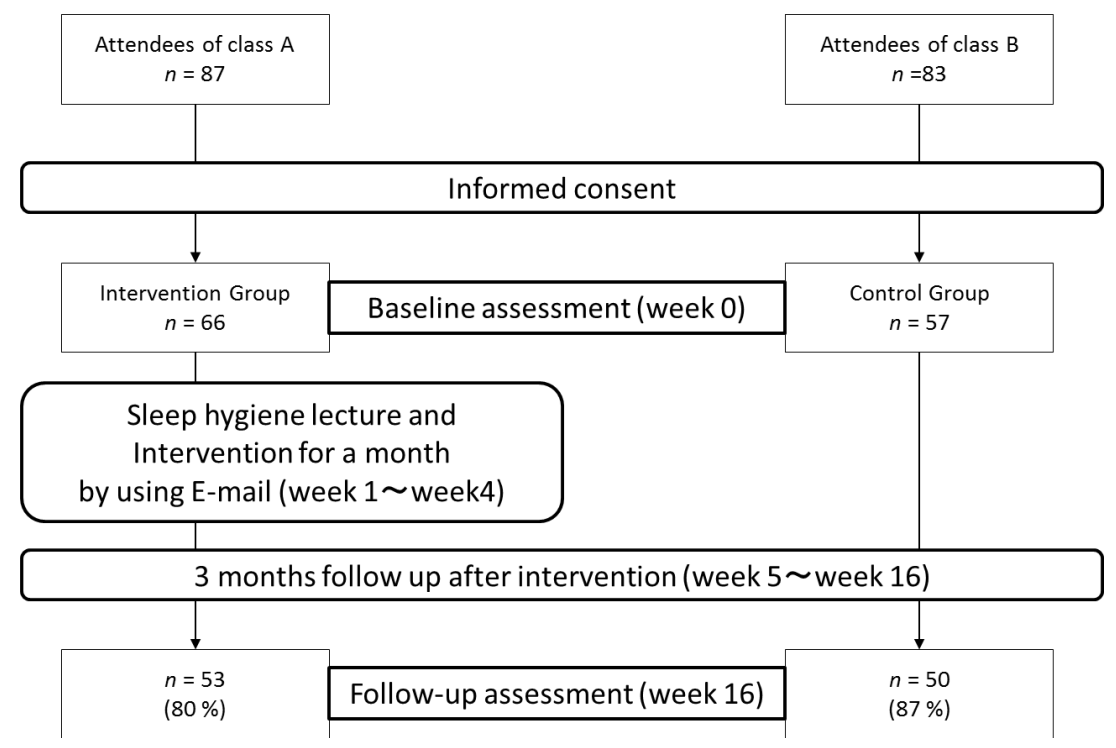

Figure 1. Flowchart representing sample sizes at the two assessments.

Table 3. Baseline assessment and group differences.

\begin{tabular}{cccc}
\hline & $\begin{array}{c}\text { Intervention } \\
(\mathrm{n}=52)\end{array}$ & $\begin{array}{c}\text { Control } \\
(\mathrm{n}=49)\end{array}$ & Significance of group difference \\
\hline $\begin{array}{c}\text { Males } \\
(\%)\end{array}$ & 17 & 28 & $\chi^{2}=6.15 ; p=01$ \\
Age & $(37.8)$ & $(62.6)$ & $\mathrm{t}=0.18 ; p=0.85$ \\
& 19.03 & 18.97 & $\mathrm{t}=0.35 ; p=0.72$ \\
PSQI & $(1.28)$ & $(1.92)$ & $\mathrm{t}=0.68 ; p=0.49$ \\
& 7.11 & $(3.44)$ & 12.81 \\
K6 & $(2.66)$ & $(6.23)$ & \\
\hline
\end{tabular}

Table 4. Change in baseline assessment to follow-up assessment in outcomes.

\begin{tabular}{|c|c|c|c|c|c|c|}
\hline & \multicolumn{2}{|c|}{ Intervention $(\mathrm{n}=52)$} & \multicolumn{2}{|c|}{ Control $(n=49)$} & \multirow{2}{*}{$\begin{array}{l}\text { Cohen's } d \\
\text { (95\% CI) }\end{array}$} & \multirow{2}{*}{$\begin{array}{c}\text { t-test } \\
p \text { value }\end{array}$} \\
\hline & Baseline & Follow-up & Baseline & Follow-up & & \\
\hline PSQI & $\begin{array}{c}7.11 \\
(2.66)\end{array}$ & $\begin{array}{c}5.82 \\
(2.81)\end{array}$ & $\begin{array}{c}6.89 \\
(3.44)\end{array}$ & $\begin{array}{c}7.14 \\
(2.66)\end{array}$ & $\begin{array}{c}0.59 \\
(0.51 \text { to } 2.56)\end{array}$ & $\begin{array}{c}\mathrm{t}=2.96 \\
p=0.004\end{array}$ \\
\hline K6 & $\begin{array}{l}13.57 \\
(4.88)\end{array}$ & $\begin{array}{l}11.50 \\
(4.85)\end{array}$ & $\begin{array}{l}12.81 \\
(6.23)\end{array}$ & $\begin{array}{l}13.57 \\
(7.07)\end{array}$ & $\begin{array}{c}0.61 \\
(0.21 \text { to } 1.01)\end{array}$ & $\begin{array}{c}\mathrm{t}=3.06 \\
p=0.003\end{array}$ \\
\hline
\end{tabular}




\section{Discussion}

In this study, we developed a 4-week e-mail program based on brief CBTI to treat and prevent college students from developing sleep and associated psychiatric problems. The aim was to use a quasi-experimental design to test the efficacy of our program.

First of all, the present dropout rates were revealing. We had a $20 \%$ dropout rate in the intervention group and a corresponding rate of $13 \%$ in the control group. These data are consistent with previous reports which show almost identical dropout rates, though our participants were a sample of students including those without significant sleep problems [23] [24]. This result indicates that our program can maintain sufficient motivation of students to improve their sleep.

According to the change of PSQI score, our program showed a sufficient effect sizes on the basis of our sample size calculation. Most previous research has targeted only patients or students with sleep problems [23] [24]. But, our study examined potential preventive effects with a sample of healthy controls without sleep problems, finding evidence of both acute treatment and prevention effects. To treat or prevent sleep problems, stepped care principles are recommended [31]. From this point of view, it is important to deliver CBTI to students as the least restrictive therapy. The least restrictive therapy should be a readily accessible form of treatment, provided at the lowest cost, least personal inconvenience to patients, requiring the lowest treatment intensity and least specialist time [32]. Our program can be a new choice of least restrictive therapy for students.

According to the change of K6 score, our program was also associated with reductions in symptoms of depression and anxiety. In Asia, it is reported that $4.0 \%$ of college students can be diagnosed with major depression [33]. In the U.S. and Canada, prevalence rates for any depressive or anxiety disorder are around $15.6 \%$ for undergraduates and $13.0 \%$ for graduate students [34]. Our program appears to have beneficial effects on such symptoms in college students and can be a choice to treat and prevent symptoms of depression and anxiety as least restrictive therapy in symptoms of depression and anxiety.

Although the present study provides some valuable findings, its design imposes the following limitations: 1) This study was conducted only at one college, which results in limited generalizability of its conclusions. 2) This was a non-randomized trial. We cannot therefore conclusively rule out pre-existing group differences as an explanation for our findings despite equivalent PSQI and K6 scores at baseline, and as noted earlier, our intervention group included more females than the control group. It remains unknown whether the observed improvements in sleep quality and mental health severity are related to the natural course of these patterns or sex. 3) The lack of long-term follow-up data limits the generalizability of the study's conclusions in terms of longer-term outcomes. This is an important consideration when evaluating the effectiveness of preventive CBT interventions, given that many previous studies have not assessed long-term outcomes. It should be considered that the longerterm effects, associated relapse rates, cost-effectiveness characteristics, etc. of CBT require further investigation. 4) Medications taken by participants were not considered in this trial.

Future studies should replicate these findings and randomized controlled trials should be conducted with larger and more diverse samples across longer follow-up periods. Despite several limitations, this quasi-experimental study suggests that sleep hygiene and an e-mail-based brief CBTI program is an effective and feasible treatment for college students. Further controlled trials that address the limitations of this study are required.

\section{References}

[1] Curcio, G., Ferrara, M. and De Gennaro, L. (2006) Sleep Loss, Learning Capacity and Academic Performance. Sleep Medicine Reviews, 10, 323-337. http://dx.doi.org/10.1016/j.smrv.2005.11.001

[2] Giri, P., Baviskar, M. and Phalke, D. (2013) Study of Sleep Habits and Sleep Problems among Medical Students of Pravara Institute of Medical Sciences Loni, Western maharashtra, India. Annals of Medical and Health Sciences Research, 3, 51-54. http://dx.doi.org/10.4103/2141-9248.109488

[3] Kwan, M.Y., Faulkner, G.E., Arbour-Nicitopoulos, K.P., et al. (2013) Prevalence of Health-Risk Behaviours among Canadian Post-Secondary Students: Descriptive Results from the National College Health Assessment. BMC Public Health, 13, 548. http://dx.doi.org/10.1186/1471-2458-13-548

[4] Thomée, S., Härenstam, A. and Hagberg, M. (2012) Computer Use and Stress, Sleep Disturbances, and Symptoms of Depression among Young Adults-A Prospective Cohort Study. BMC Psychiatry, 12, 176. http://dx.doi.org/10.1186/1471-244X-12-176

[5] Perez-Chada, D., Perez-Lloret, S., Videla, A.J., et al. (2007) Sleep Disordered Breathing and Daytime Sleepiness Are 
Associated with Poor Academic Performance in Teenagers. A Study Using the Pediatric Daytime Sleepiness Scale (PDSS). Sleep, 30, 1698-1703.

[6] Lund, H.G., Reider, B.D., Whiting, A.B., et al. (2010) Sleep Patterns and Predictors of Disturbed Sleep in a Large Population of College Students. The Journal of Adolescent Health, 46, 124-132.

http://dx.doi.org/10.1016/j.jadohealth.2009.06.016

[7] Taylor, D.J., Bramoweth, A.D., Grieser, E.A., et al. (2013) Epidemiology of Insomnia in College Students: Relationship with Mental Health, Quality of Life, and Substance Use Difficulties. Behavior Therapy, 44, 339-348. http://dx.doi.org/10.1016/j.beth.2012.12.001

[8] Lopresti, A.L., Hood, S.D. and Drummond, P.D. (2013) A Review of Lifestyle Factors That Contribute to Important Pathways Associated with Major Depression: Diet, Sleep and Exercise. Journal of Affective Disorders, 148, 12-27. http://dx.doi.org/10.1016/j.jad.2013.01.014

[9] Nyer, M., Farabaugh, A. and Fehling, K., et al. (2013) Relationship between Sleep Disturbance and Depression, Anxiety, and Functioning in College Students. Depression and Anxiety, 30, 873-880. http://dx.doi.org/10.1002/da.22064

[10] Edinger, J.D. and Means, M.K. (2005) Cognitive-Behavioral Therapy for Primary Insomnia. Clinical Psychology Review, 25, 539-558. http://dx.doi.org/10.1016/j.cpr.2005.04.003

[11] Morin, C.M., Bootzin, R.R., Buysse, D.J., Edinger, J.D., Espie, C.A. and Lichstein, K.L. (2006) Psychological and Behavioral Treatment of Insomnia: Update of the Recent Evidence (1998-2004). Sleep, 29, 1398-1414.

[12] Sivertsen, B., Omvik, S., Pallesen, S., Bjorvatn, B., Havik, O.E., Kvale, G., et al. (2006) Cognitive Behavioral Therapy vs. Zopiclone for Treatment of Chronic Primary Insomnia in Older Adults: A Randomized Controlled Trial. Journal of the American Medical Association, 295, 2851-2858. http://dx.doi.org/10.1001/jama.295.24.2851

[13] Watanabe, N., Furukawa, T.A., Shimodera, S., Morokuma, I., Katsuki, F., Fujita, H., et al. (2011) Brief Behavioral Therapy for Refractory Insomnia in Residual Depression: An Assessor-Blind, Randomized Controlled Trial. The Journal of Clinical Psychiatry, 72, 1651-1658. http://dx.doi.org/10.4088/JCP.10m06130gry

[14] Perils, M.L. and Smith, M.T. (2008) How Can We Make CBT-I and Other BSM Services Widely Available? Journal of Clinical Sleep Medicine, 4, 11-13.

[15] Unbehaun, T., Spiegelhalder, K., Hirscher, V. and Riemann, D. (2010) Management of Insomnia: Update and New Approaches. Nature and Science of Sleep, 2, 127-138.

[16] Ström, L., Pettersson, R. and Andersson, G. (2004) Internet-Based Treatment for Insomnia: A Controlled Evaluation. Journal of Consulting and Clinical Psychology, 72, 113-120. http://dx.doi.org/10.1037/0022-006X.72.1.113

[17] Ritterband, L.M., Thorndike, F.P., Gonder-Frederick, L.A., Magee, J.C., Bailey, E.T., Saylor, D.K. and Morin, C.M. (2009) Efficacy of an Internet-Based Behavioral Intervention for Adults with Insomnia. Archives of General Psychiatry, 66, 692-698. http://dx.doi.org/10.1001/archgenpsychiatry.2009.66

[18] Espie, C.A., Kyle, S.D., Williams, C., Ong, J.C., Douglas, N.J., Hames, P. and Brown, J.S. (2012) A Randomized, Placebo-Controlled Trial of Online Cognitive Behavioral Therapy for Chronic Insomnia Disorder Delivered via an Automated Media-Rich Web Application. Sleep, 35, 769-781.

[19] Lancee, J., van den Bout, J. and van Straten, A. and Spoormaker, V.I. (2012) Internet-Delivered or Mailed Self-Help Treatment for Insomnia? A Randomized Waiting-List Controlled Trial. Behaviour Research and Therapy, 50, 22-29. http://dx.doi.org/10.1016/j.brat.2011.09.012

[20] Brown, F.C., Buboltz, W.C. and Soper, B. (2002) Relationship of Sleep Hygiene Awareness, Sleep Hygiene Practices, and Sleep Quality in University Students. Behavioral Medicine, 28, 33-38. http://dx.doi.org/10.1080/08964280209596396

[21] Brown, F.C., Buboltz, W.C. and Soper, B. (2006) Development and Evaluation of the Sleep Treatment and Education Program for Students (STEPS). Journal of American College Health, 54, 231-237. http://dx.doi.org/10.3200/JACH.54.4.231-237

[22] Quan, S.F., Anderson, J.L. and Hodge, G.K. (2013) Use of a Supplementary Internet Based Education Program Improves Sleep Literacy in College Psychology Students. Journal of Clinical Sleep Medicine, 9, 155-160.

[23] Trockel, M., Manber, R., Chang, V., Thurston, A. and Taylor, C.B. (2011) An E-Mail Delivered CBT for Sleep-Health Program for College Students: Effects on Sleep Quality and Depression Symptoms. Journal of Clinical Sleep Medicine, 7, 276-281.

[24] Bjorvatn, B., Fiske, E. and Pallesen, S. (2011) A Self-Help Book Is Better Than Sleep Hygiene Advice for Insomnia: A Randomized Controlled Comparative Study. Scandinavian Journal of Psychology, 52, 580-585. http://dx.doi.org/10.1111/j.1467-9450.2011.00902.x

[25] Faul, F., Erdfelder, E., Lang, A.G. and Buchner, A. (2007) G*Power 3: A Flexible Statistical Power Analysis Program for the Social, Behavioral, and Biomedical Sciences. Behavior Research Methods, 39, 175-191. 
http://dx.doi.org/10.3758/BF03193146

[26] Buysse, D.J., Reynolds, C.F., Monk, T.H., Berman, S.R. and Kupfer, D.J. (1989) The Pittsburgh Sleep Quality Index: A New Instrument for Psychiatric Practice and Research. Psychiatry Research, 28, 193-213. http://dx.doi.org/10.1016/0165-1781(89)90047-4

[27] Doi, Y., Minowa, M., Uchiyama, M., Okawa, M., Kim, K., Shibui, K. and Kamei, Y. (2000) Psychometric Assessment of Subjective Sleep Quality Using the Japanese Version of the Pittsburgh Sleep Quality Index (PSQI-J) in Psychiatric Disordered and Control Subjects. Psychiatry Research, 97, 165-172. http://dx.doi.org/10.1016/S0165-1781(00)00232-8

[28] Kessler, R.C., Andrews, G., Colpe, L.J., Hiripi, E., Mroczek, D.K., Normand, S.L., et al. (2002) Short Screening Scales to Monitor Population Prevalences and Trends in Non-Specific Psychological Distress. Psychological Medicine, 32, 959-976. http://dx.doi.org/10.1017/S0033291702006074

[29] Furukawa, T.A., Kessler, R.C., Slade, T. and Andrews, G. (2003) The Performance of the K6 and K10 Screening Scales for Psychological Distress in the Australian National Survey of Mental Health and Well-Being. Psychological Medicine, 33, 357-362. http://dx.doi.org/10.1017/S0033291702006700

[30] Kanda, Y. (2013) Investigation of the Freely Available Easy-to-Use Software “EZR” for Medical Statistics. Bone Marrow Transplantation, 48, 452-458. http://dx.doi.org/10.1038/bmt.2012.244

[31] Espie, C.A. (2009) “Stepped Care”: A Health Technology Solution for Delivering Cognitive Behavioral Therapy as a First Line Insomnia Treatment. Sleep, 32, 1549-1558.

[32] Bower, P. and Gilbody, S. (2005) Stepped Care in Psychological Therapies: Access, Effectiveness and EfficiencyNarrative Literature Review. British Journal of Psychiatry, 186, 11-17. http://dx.doi.org/10.1192/bjp.186.1.11

[33] Chen, L., Wang, L., Qiu, X.H., Yang, X.X., Qiao, Z.X., Yang, Y.J. and Liang, Y. (2013) Depression among Chinese University Students: Prevalence and Socio-Demographic Correlates. PloS ONE, 8, e58379. http://dx.doi.org/10.1371/journal.pone.0058379

[34] Eisenberg, D., Gollust, S.E., Golberstein, E. and Hefner, J.L. (2007) Prevalence and Correlates of Depression, Anxiety, and Suicidality among University Students. The American Journal of Orthopsychiatry, 77, 534-542. http://dx.doi.org/10.1037/0002-9432.77.4.534 
Scientific Research Publishing (SCIRP) is one of the largest Open Access journal publishers. It is currently publishing more than 200 open access, online, peer-reviewed journals covering a wide range of academic disciplines. SCIRP serves the worldwide academic communities and contributes to the progress and application of science with its publication.

Other selected journals from SCIRP are listed as below. Submit your manuscript to us via either submit@scirp.org or Online Submission Portal.
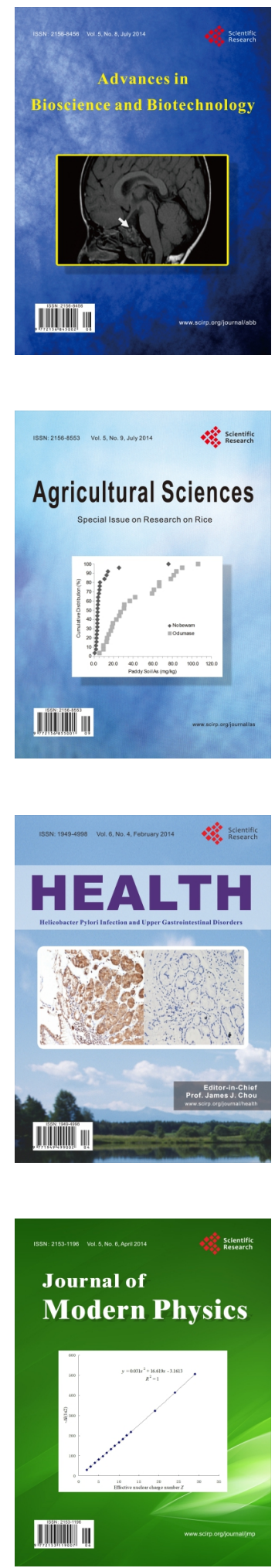
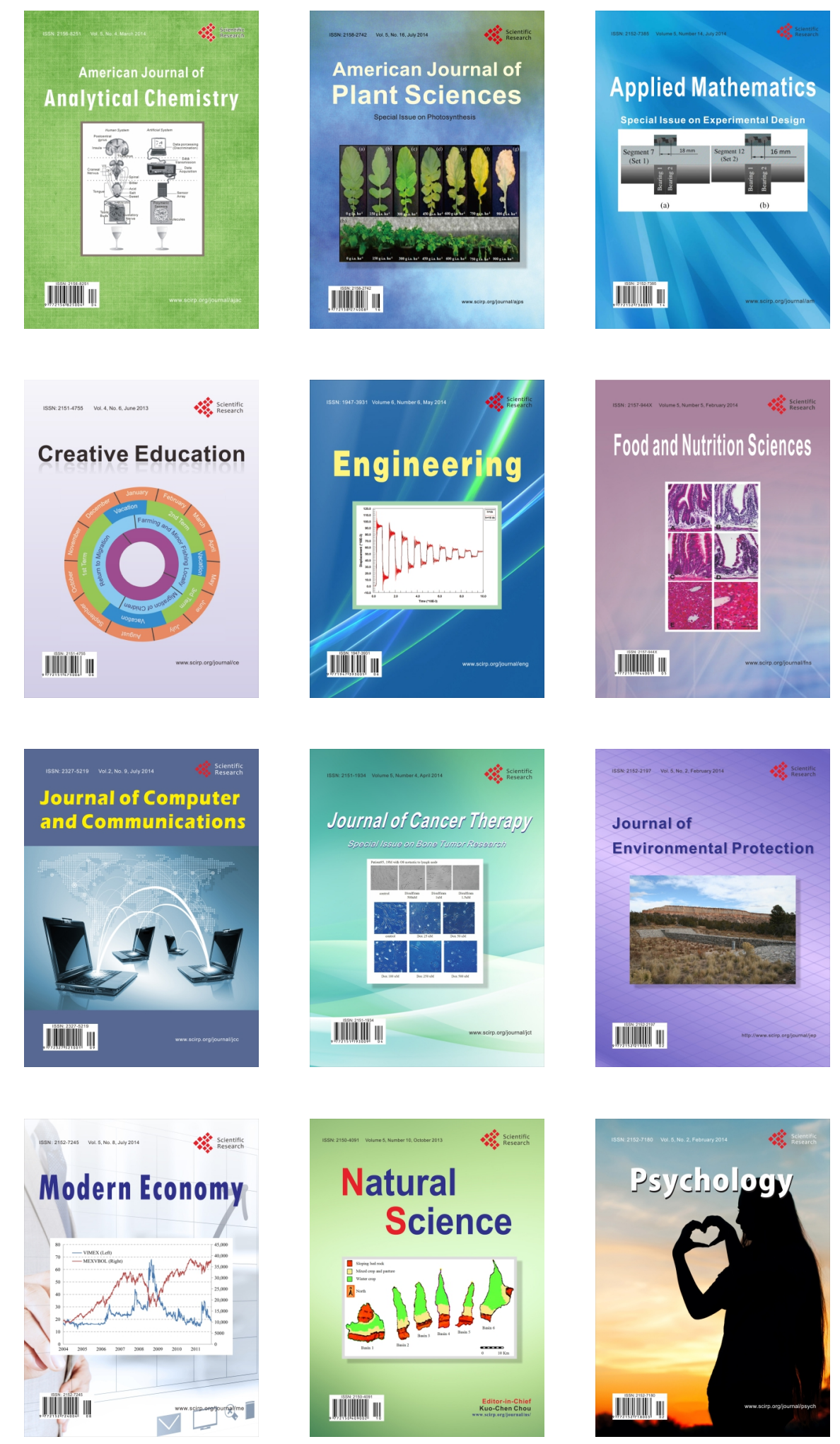